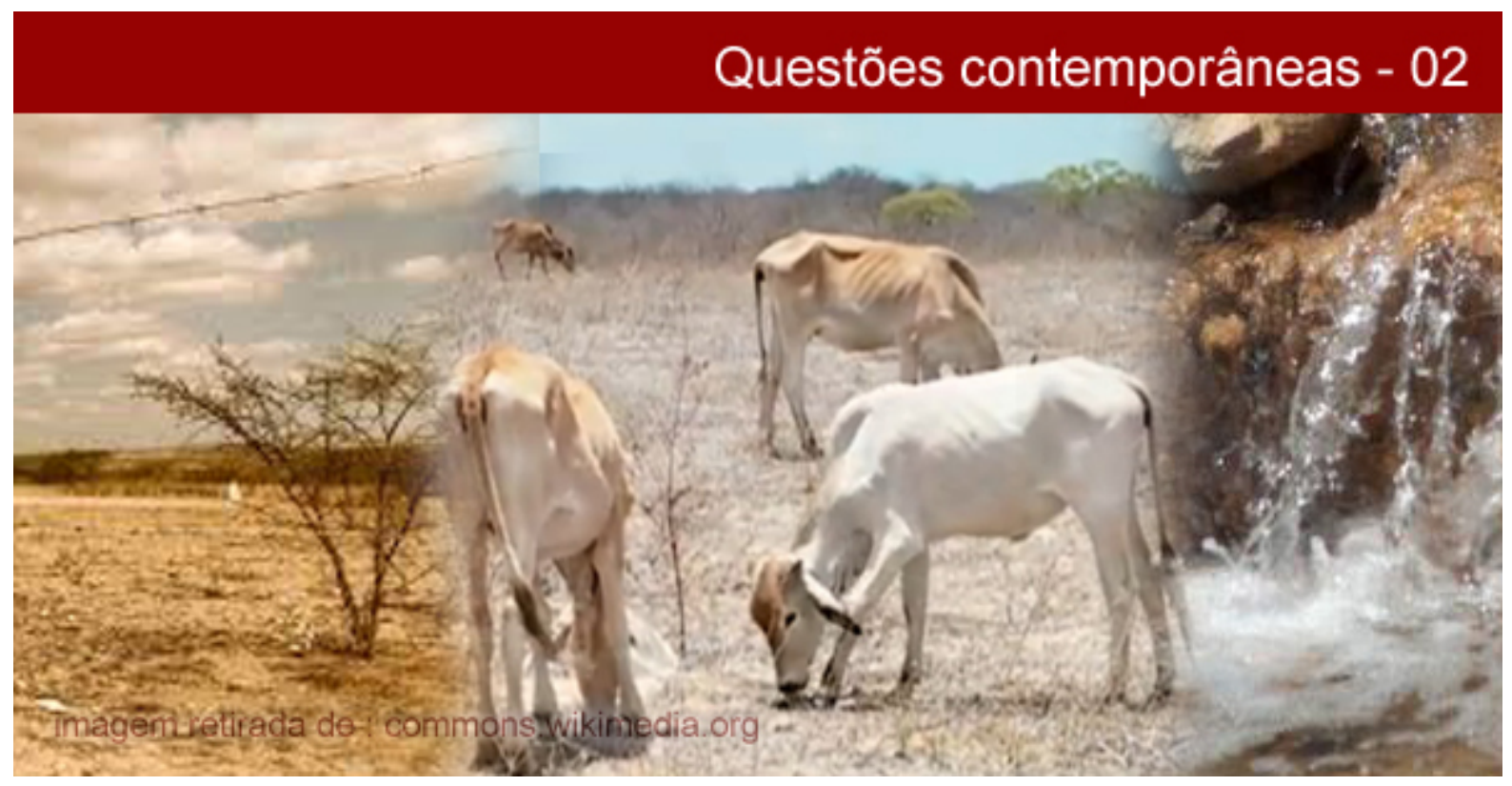

\title{
A PERCEPÇÃO DAS FAMÍLIAS DE GADO BRAVO-PB SOBRE A RELEVÂNCIA SOCIAL DA ÁGUA SUBTERRÂNEA
}

\section{Sara Camêlo Aguiar}

Mestre em Recursos Naturais pela Universidade Federal de Campina Grande /UFCG; Especialista em Políticas Públicas e Assistência Social pela Fundação de Apoio ao Ensino, Pesquisa e Extensão/FURNE, e graduada em Serviço Social pela Universidade Estadual da Paraíba/UEPB. E-mail: saracameloag@hotmail.com.

\section{João Miguel de Moraes Neto}

Doutor em Recursos Naturais pela Universidade Federal de Campina Grande/UFCG; Mestre em Engenharia Agrícola pela UFCG e graduado em Engenharia Agrícola pela Universidade Federal da Paraíba/UFPB.

\section{Luana Andrade Lima Querino}

Mestre em Recursos Naturais pela Universidade Federal de Campina Grande/UFCG; Especialista em Desenvolvimento e Meio Ambiente pela Fundação de Apoio ao Ensino, Pesquisa e Extensão/FURNE e graduada em Biologia pela Universidade Vale do Acaraú.

Resumo: O presente trabalho teve como área de pesquisa a zona rural do município de Gado Bravo, localizado na mesorregião do Agreste Paraibano, e seu objetivo consistiu em analisar a percepção das famílias sobre a relevância social da água subterrânea considerando as especificidades locais. Foi realizada uma revisão bibliográfica e empregadas uma abordagem qualitativa e uma pesquisa do tipo exploratória, na qual adotou-se como instrumento de coleta de dados uma entrevista semiestruturada, que foi aplicada a 83 famílias, o que corresponde a cerca de $5 \%$ do universo. Conforme os resultados, foi verificado que a água subterrânea possui grande relevância social, pois segundo a percepção das famílias ela é a condição essencial para a criação dos rebanhos, que é a principal atividade econômica do município; sua presença é sinônimo de riqueza e é associada frequentemente à religiosidade das famílias.

Palavras-chave: Percepção. Relevância. Água subterrânea. Famílias.

\section{THE PERCEPTION OF THE FAMILIES OF GADO BRAVO-PB ON THE SOCIAL RELEVANCE OF GROUNDWATER}

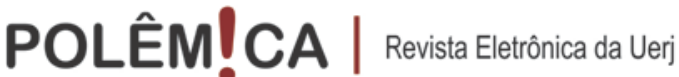


Abstract: This study was to research the rural municipality of Gado Bravo, located in the middle region of the Paraíba arid, and its purpose was to analyze the perception of households on the social relevance of groundwater considering the local conditions. A literature review was conducted and its employed a qualitative approach and adopted a exploratory survey, which was adopted as data collection instrument an semi-structured interview that was applied to 83 families, representing about 5\% of the universe. According to the results it was found that groundwater has great social relevance, because according to the perception of the families it is the essential condition for the creation of herds, which is the main economic activity of the municipality; its presence is synonymous with wealth and is often associated the religious families.

Keywords: Perception. Relevance. Groundwater. Families.

\section{Introdução}

Água subterrânea é toda a água que flui abaixo da superfície da Terra e preenche os poros ou vazios intergranulares das rochas sedimentares, ou as fraturas, falhas e fissuras das rochas cristalinas, e quando submetida às forças de adesão e de gravidade exerce uma função fundamental no mantimento da umidade do solo, do fluxo dos rios, lagos e brejos (BORGHETTI et al., 2004).

Em 2001, a exploração de água subterrânea, medida em milhões de toneladas por ano, chegou a mais de 600.000, enquanto que outros recursos naturais bastante explorados, como o petróleo e o ferro, alcançaram, respectivamente, 3.560 e 662 (EARTH SCIENCES SOCIETY FUNDATION, 2005).

O Nordeste detém o menor volume hídrico superficial brasileiro, consequentemente, o uso da água subterrânea se avulta na região, sobretudo em $53 \%$ do seu território, que corresponde à extensão de abrangência do clima semiárido. As reservas de águas subterrâneas no semiárido nordestino são estimadas em 500 milhões de metros cúbicos por ano (PARAÍBA, 1985). A escassez de água superficial associada à existência de água subterrânea na região torna essa última uma variável importante, tanto para a subsistência quanto para o desenvolvimento de sua população; consiste, portanto, em um recurso estratégico para a região Nordeste (CPRM, 2001).

O problema da escassez de água superficial no semiárido nordestino, portanto, deve ser abordado juntamente com as alternativas presentes na região. Nesse sentido, a água subterrânea desponta no semiárido como uma segunda opção de acesso à água, que subsidia inúmeras ideias e proposições de convivência da população com as secas.

\section{Percepção ambiental e a água subterrânea}

\section{POLÊM!CA | Revista Eletronica da Ueri}


A palavra percepção tem origem latina e é derivada do termo perception; ela significa: “Ato, efeito ou faculdade de perceber; recepção, pelos centros nervosos, de impressões colhidas pelos sentidos” (MICHAELIS, 2009, não paginado).

A percepção se dá a partir da associação entre as atividades dos órgãos dos sentidos e as atividades cerebrais; essa associação se desenvolve conforme a funcionalidade dos sentidos e mediante isso a percepção acontece de forma diferente em cada indivíduo, pois o significado despertado pelos estímulos sensoriais diferencia a forma como cada indivíduo compreende sua realidade (OLIVEIRA, CORONA, 2008).

Segundo Filho e Braga (2009), sob o ponto de vista cultural, o modo de vida e as relações sociais fragmentam a percepção dos indivíduos, tornando-os impossibilitados de compreenderem a complexidade de cada ação e desprovidos de pensamento crítico, e isso os leva a crer na existência de apenas uma reação para cada ação. Isto é, o indivíduo frente ao seu cotidiano não o percebe enquanto um todo complexo composto por ações e reações concatenadas.

A ausência de visão crítica e de reflexão no tocante às relações entre os indivíduos e o ambiente, e entre os próprios indivíduos, inserida nos marcos do modo de produção capitalista, fez com que as cidades bem como o planeta se dirigissem a uma crise socioambiental multidimensional (FILHO, BRAGA, 2009).

Diante disso e de suas consequências danosas, a expressão “percepção ambiental” tomou sentido e possui vários conceitos, porém vale salientar que, em todos eles, o elemento fundamental a ser destacado são as relações entre o homem e o meio ambiente, como cada indivíduo o percebe, o quanto conhece do seu próprio meio, o que espera do seu meio, como o utiliza e sua ação cultural sobre esse meio (CUNHA, LEITE, 2009). Ou seja, a percepção ambiental se dá no momento em que o indivíduo toma consciência do seu meio, quando ele formula um julgamento a seu respeito considerando os fatores políticos, econômicos e sociais que o compõe. Essa representação do indivíduo ou coletividade sobre o ambiente é direcionada conforme seus valores, crenças e identidades.

A percepção abrange a seleção, a identificação e a codificação de informações importantes, dentro de um contexto relembrado de informações passadas. Os comportamentos do indivíduo ou coletividade estão de acordo com o que a cultura admite como informação 
verdadeira, isto é, que esteja em conformidade com as representações de determinada sociedade (VASCO, ZAKRZEVSKI, 2010).

Além da cultura a percepção ambiental também é influenciada pelo sistema normativo e pelo modelo de desenvolvimento definidos para cada região. As leis norteiam o julgamento dos indivíduos no que concerne aos comportamentos considerados certos ou errados diante do meio ambiente, já o modelo de desenvolvimento intervém na forma como os recursos naturais são manejados pelo homem e, por conseguinte, na qualidade ambiental e na vida da população (VASCO, ZAKRZEVSKI, 2010).

O estudo da percepção ambiental encontra-se em um aspecto próprio das interações entre o homem e o meio ambiente, uma vez que é uma aproximação na qual a apreensão do meio ambiente por parte do homem é considerada como um dos elementos determinantes que particulariza aquele ambiente, isto é, a conduta humana singulariza o ambiente no qual ela está inserida. A partir disso é possível investigar qual a percepção que as pessoas têm do seu meio ambiente; como a cultura e a experiência influenciam essa percepção; quais as atitudes em relação ao meio ambiente; e qual a função que a percepção ambiental desempenha no arranjo espacial do meio ambiental e na configuração das paisagens.

Nesse sentido, devido às particularidades que a percepção ambiental pode assumir segundo a cultura, as leis e o modelo de desenvolvimento de cada população, e em função do papel fundamental da gestão dos diferentes ambientes e paisagens, o estudo da percepção ambiental é basilar para compreender como os ambientes e paisagens são percebidos pelo indivíduo ou coletividade, para conhecer a real exposição que eles estão sujeitos e para a elaboração de planejamentos e políticas. Porém, isso não tem acontecido, pois o conhecimento a fundo da população a respeito dos problemas sociais, econômicos, políticos e ambientais não condiz com os interesses do capitalismo. 
O conhecimento prévio da percepção ambiental daqueles que utilizam os recursos naturais é peça-chave para o desenvolvimento e sustentabilidade das ações incidentes sobre eles. Os recursos hídricos, por sua vez, são um grande exemplo de como um recurso natural pode ser afetado conforme o entendimento dos indivíduos que o utilizam. Dentre as várias formas em que a água se encontra distribuída no planeta, tem-se a água subterrânea, que é mais utilizada nas regiões de clima semiárido. Assim, o estudo da percepção ambiental nesse contexto demonstra a importância do papel que desempenha ao destacar para quem a utiliza uma fonte de acesso à água quase que exclusiva em períodos de estiagem, bem como ao oferecer novas proposições para um uso mais racional da água subterrânea.

Desse modo, o objetivo do presente estudo foi analisar a percepção das famílias da zona rural de Gado Bravo sobre a relevância social da água subterrânea.

\section{Método}

O município de Gado Bravo se localiza na mesorregião do Agreste Paraibano, entre as coordenadas geográficas $07^{\circ} 34^{\prime} 58^{\prime \prime}$ de latitude Sul e 35²7’27” de longitude Oeste (CIDADE BRASIL, 2012). A escolha de Gado Bravo enquanto área de pesquisa se deve à forte utilização da água subterrânea para a dessedentação animal dos rebanhos, que, por sua vez, consistem na principal atividade econômica e fonte de renda no município.

A realização do estudo teve uma abordagem qualitativa e adotou uma pesquisa do tipo exploratória. O instrumento de coleta de dados empregado foi uma entrevista semiestruturada aberta com perguntas abordando a utilização, a importância e as alternativas à água subterrânea. As respostas foram gravadas com um aparelho celular. Segundo Sarmento (1994), a entrevista possibilita um diálogo que se realiza ao passo que o real é conhecimento.

Foi utilizada uma amostra de 83 famílias, o que corresponde a 5\% do universo de famílias da zona rural de Gado Bravo. A seleção da revisão bibliográfica, conforme conteúdos afins ao tema estudado, e a escolha da metodologia se deram em junho de 2014, enquanto a coleta e análise dos dados se deram no período de julho a novembro do mesmo ano.

\section{Análise dos resultados}


Para analisar a percepção das famílias da zona rural de Gado Bravo sobre a relevância social da água subterrânea, os(as) entrevistados(as) foram indagados(as): "Em quais atividades a água subterrânea é utilizada?”, notoriamente eles (as) responderam:

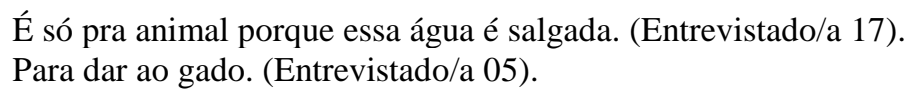

Segundo as respostas dos (as) entrevistados (as), o uso mais expressivo da água subterrânea em Gado Bravo é para uso animal, tal utilidade foi mencionada de forma quase absoluta entre eles (as). Isso se deve a dois fatos, o primeiro é a forte presença da pecuária leiteira, que consiste na principal atividade econômica da zona rural do município, e o segundo é a escassez de água superficial em função da irregularidade das chuvas na região e a ausência e/ou ineficiência das políticas públicas voltadas para a convivência da população com os efeitos das secas.

As políticas públicas voltadas para minimização dos efeitos das secas, até então empreendidas no Nordeste, se mostraram incompletas e desintegradas, uma vez que a sucessão de governos implica na alteração dos projetos de governos anteriores (PASSADOR, PASSADOR, 2010). Além disso, são ações caracteristicamente acompanhadas por forte apelo eleitoreiro.

Além do uso animal, na zona rural de Gado Bravo a água subterrânea é utilizada para afazeres de higiene doméstica e pessoal:

\footnotetext{
Usa para os animais e quando tá muito seco a gente também usa em casa, pra limpeza em geral de casa. (Entrevistado/a 08).

Pro gado, pra casa, assim, quando não tem a gente usa pra lavar até prato, até banho agente tomou com ela. (Entrevistado/a 80).
}

Isto é, a necessidade é quem dita a utilidade que a água subterrânea possui; independentemente de ser adequada ou não, é ela quem socorre as famílias durante as secas. Vale destacar que não são realizadas análises das águas explotadas pelos poços do município, o que exclui qualquer possibilidade de enquadramento correto para o uso da água subterrânea em Gado Bravo, conforme a Resolução CONAMA nº 396 de 2008 (BRASIL, 2008).

Para aprofundar a análise da percepção das famílias da zona rural de Gado Bravo sobre a relevância social da água subterrânea, os(as) entrevistados(as) foram questionados(as): 
“Em períodos de estiagem existem outras fontes de acesso à água além da água subterrânea?”, assim responderam:

A outra fonte é as cisternas. (Entrevistado/a 11).

Tem a da cisterna, mas ninguém vai dar água de cisterna a gado, né? (Entrevistado/a 67).

Além da água subterrânea, outra ferramenta de enfretamento aos efeitos das secas em Gado Bravo é a cisterna utilizada para armazenar água, porém esta geralmente se destina para o uso doméstico e humano, uma vez que comumente essa água provém da chuva, da compra de carradas d’água ou da distribuição de carradas d’água através da Operação Carro-Pipa. Os(as) entrevistados(as) consideram a água das cisternas como "doce”, e outro uso que não seja doméstico ou humano, como a dessedentação animal, é considerado um desperdício. A água “doce” para consumo animal é somente aquela que é armazenada em açudes, barragens e barreiros, mas a acumulada nas cisternas está "guardada” para o consumo humano.

Fonte alternativa de acesso à água, citada acima, a Operação Carro-Pipa consiste em uma parceria do Ministério da Integração Nacional, através da Secretaria Nacional de Defesa Civil, com o Exército Brasileiro, que atende especialmente aos municípios do semiárido brasileiro (BRASIL, 2014). Na prática, pipeiros do próprio município são indicados pela Prefeitura Municipal e contratados pelo Governo Federal para distribuírem carradas d’água, em tese, periodicamente, nas cisternas que são previamente cadastradas. Cada cisterna se destina ao uso da família a qual ela pertence e das famílias vizinhas.

Só a do exército. (Entrevistado/a 54),

Em cisternas cadastradas pelo exército. (Entrevistado/a 07).

Não, é ela e outra só se for a água do exército quando tem. (Entrevistado/a 18).

Conforme é mencionado pelos(as) próprios(as) entrevistados(as), “a água do exército” possui grande importância na zona rural de Gado Bravo, porém a periodicidade da distribuição das carradas d’água é bastante irregular e muitas vezes essa água falta e não há o que fazer, senão esperar a próxima carrada d’água. Além disso, a quantidade da água distribuída pela Operação Carro-Pipa é muito aquém da demanda das famílias que são referenciadas por uma única cisterna cadastrada, principalmente as que possuem um número maior de famílias, uma vez que não há uma quantidade exata a serem abastecidas por cada cisterna. 
Outra forma de acesso à água nos períodos de estiagem, além da água subterrânea, é a compra de carradas d’água:

Só comprada, tem que comprar água quando não tem no poço. (Entrevistado/a 49).

A compra de água é proporcional ao aumento da escassez da água proveniente das chuvas, da Operação Carro-Pipa e também quando os poços artesianos e suas instalações apresentam defeitos e não conseguem explotar a água subterrânea. Isso demonstra que a compra de carradas d’água em Gado Bravo é a última alternativa de obtenção de água, sobretudo porque quando a demanda aumenta, conforme o período de estiagem se prolonga, o valor das carradas d’água consequentemente encarece e, essa aquisição se torna muito onerosa para o orçamento financeiro das famílias, que é ainda mais fragilizado durante a seca devido às perdas agrícolas e à queda de preço de seus rebanhos, comuns nesse período.

E por último foi efetuada a pergunta: "Você acha a água subterrânea importante nos períodos de estiagem?”, os(as) entrevistados(as) disseram:

Claro que sim! Porque de primeiro quando não tinha ela aqui era pior. (Entrevistado/a 17).

É demais! Nossa Senhora! É a salvação! (Entrevistado/a 54).

É notória a importância associada à água subterrânea pelos(as) entrevistados(as); é dado um status de essencialidade, de sinônimo de melhoria, e chega a ser dissertada juntamente com expressões características da religiosidade desses(as) entrevistados(as). Conforme Martinez (2002), a religiosidade dos nordestinos além de renovar esperanças em dias melhores converte-se em fator de "promoção social” em condições diferentes às que são postas pelas secas.

Isso é reflexo do papel desempenhado pela água subterrânea no dia a dia da zona rural de Gado Bravo, pois muitas vezes ela é condição de sobrevivência animal e até humana, uma vez que os rebanhos dependem fundamentalmente da água subterrânea e estes constituem a principal fonte de renda das famílias.

Ainda conforme as respostas a respeito da importância da água subterrânea, os (as) entrevistados(as), ao suporem ou relembrarem caso de sua ausência, se veem diante de uma situação de adversidade e fatalidade:

Ah... Demais, se não fosse ela a gente tava perdido! (Entrevistado/a 12). 
Muito importante, porque se não fosse ela o que era de nós? (Entrevistado/a 45).

Isto é, os (as) entrevistados (as) percebem a água subterrânea como um amparo, uma sustentação no dia a dia que os protege de situações adversas.

\section{Conclusões e Considerações}

Com as respostas dadas pelos (as) entrevistados (as) fica expressivamente comprovado que as famílias da zona rural de Gado Bravo percebem a água subterrânea como um recurso de grande relevância social para o dia a dia, pois ela é dissertada como condição essencial para a criação dos rebanhos do município, que consiste na principal atividade econômica e meio de sobrevivência dessas famílias; além disso, é utilizada para afazeres domésticos e de higiene. Fato que faz frente aos efeitos das frequentes e longas estiagens e ao descaso do poder público.

A ausência da água subterrânea implica, sobretudo, na necessidade da compra de carradas d’água que é bastante onerosa para as famílias que, em geral, possuem baixos rendimentos.

Em resumo, a razão de a água subterrânea possuir grande relevância social para as famílias da zona rural de Gado Bravo está na essencialidade desempenhada por ela no cotidiano dessas famílias, fato atestado inclusive com expressões de fé.

\section{Referências}

BORGHETTI, N. R. B; et al. Aquífero Guarani: A verdadeira Integração dos Países do Mercosul. Rio de Janeiro: Fundação Roberto Marinho, 2004.

BRASIL. Ministério do Meio Ambiente. Resolução CONAMA n 396, de abril de 2008. Dispõe sobre a classificação e diretrizes ambientais para o enquadramento das águas subterrâneas e dá outras providências. Disponível em: <www.mma.gov.br/port/conama/.../CONAMA_RES_CONS_2008_3696.pdf.>. Acesso em: 28 nov. 2014.

BRASIL. Observatório da seca. Operação carro-pipa. 2014. Disponível em:

<www.brasil.gov.br/observatoriodaseca/operacao-carro-pipa.html>. Acesso em: 08 set. 2014.

CIDADE BRASIL. Município de Gado Bravo. 2012. Disponível em: <www.cidade-brasil.com.br/municipiogado-bravo.html>. Acesso em: 23 dez. 2014.

COMPANHIA DE PESQUISA DE RECURSOS MINERAIS - CPRM. Programa de água subterrânea para a região Nordeste. 2001. Disponível em: <www.cprm.gov.br/arquivos/pdf/dehid/prgaguaregne.pdf >. Acesso em: 14 jan. 2015. 
CUNHA, A. S. da; LEITE, E. B. Percepção Ambiental: implicações para a Educação Ambiental. Sinapse Ambiental, 2009. Disponível em:

<http://www.pucminas.br/graduacao/cursos/arquivos/ARE_ARQ_REVIS_ELETR20090930145741.pdf>. Acesso em: 07 jun. 2014.

EARTH SCIENCES FOR SOCIETY FUNDATION. Água Subterrânea - Reservatório para um planeta com sede? 2005. Disponível em: <www.yearofplanetearth.org/content/downloads/.../brochura2_web.pdf>. Acesso em: 01 set. 2014.

FILHO, L. V. S.; BRAGA, M. C. B. Abordagem para o desenvolvimento de questionário de percepção ambiental em uma Bacia Hidrográfica Urbana. In: Anais do XVIII Simpósio Brasileiro de Recursos Hídricos. Campo Grande, 22-26 de nov., 2009.

MARTINEZ, Paulo Henrique. Vida e morte no sertão: histórias das secas no Nordeste nos séculos XIX e XX. Revista Brasileira de História [online]. 2002, vol. 22, n.43, pp. 251-254. ISSN 1806-9347. Disponível em: <www.scielo.br/scielo.php?acript=sci_arttext\&pid=S0102...>. Acesso em: 25 set. 2014.

MICHAELIS. Dicionário de Português Online. 2009. Disponível em: <michaelis.uol.com.br>. Acesso em: 07 jun. 2014.

OLIVEIRA, K. A.; CORONA, H. M. P. A Percepção Ambiental como ferramenta de propostas educativas e de Políticas Ambientais. Revista Científica ANAP Brasil, v. 1, n.1. Paraná, 2008.

PARAÍBA. Superintendência do Desenvolvimento do Nordeste - SUDENE. Recursos Naturais do Nordeste: investigação e potencial. Sumário das Atividades. Recife. 4 ed. 1985.

PASSADOR, C. S.; PASSADOR, J. L. Apontamentos sobre as políticas públicas de combate à seca no Brasil: cisternas e cidadania? Cadernos Gestão Pública e Cidadania, v. 15, n. 56. São Paulo, 2010.

SARMENTO, H. B. de M. Instrumentos e técnicas em serviço social: elementos para uma rediscussão. Dissertação. PUC, São Paulo, 1994.

VASCO, A. ZAKRZEVSKI, S. B. B. O estado da arte das pesquisas sobre percepção ambiental no Brasil. Revista Perspectiva, v. 34, n. 125. Rio Grande do Sul, 2010.

Recebido em: 28/03/2015.

Aceito em: 22/06/2015. 